\title{
Politicizing Brandom's Pragmatism: Normativity and the Agonal Character of Social Practice
}

Thomas Fossen

Department of Philosophy, Utrecht University

Thomas.Fossen@phil.uu.nl

Forthcoming in European Journal of Philosophy

\begin{abstract}
:
This article provides an agonistic interpretation of Robert Brandom's social-pragmatic account of normativity. I argue that social practice, on this approach, should be seen not just as cooperative, but also as contestatory. This aspect, which has so far remained implicit, helps to illuminate Brandom's claim that normative statuses are 'instituted' by social practices: normative statuses are brought into play in mutual engagement, and are only in play from an engaged social perspective among others. Moreover, in contrast to a positivist or conventionalist understanding of Brandom's work, it shows that the possibility of a critical stance toward existing practices is not only compatible with, but already implicit in this form of pragmatism. This can be made explicit with the notion of farcical practices: practices that are treated merely as if they institute genuine commitments and entitlements. Interpreting a practice as farcical is taking a critical stance toward it, and this possibility is inherent in Brandom's theoretical framework. This opens the way for a fruitful appropriation of Brandom's pragmatism for social and political philosophy.
\end{abstract}




\section{Introduction}

Pragmatist approaches to normativity affirm a kind of primacy of practice: they seek to account for the bindingness of norms in terms of social practices. Part of the appeal of such approaches is that they are (or purport to be) light on metaphysical and epistemic presuppositions, avoiding dualisms such as those between mind and world or subject and object. For instance, at the level of the theory of meaning, pragmatist approaches try to explain the correctness of applications of concepts (what words really mean) in first instance in terms of their use (how they are treated by those who deploy them), rather than in terms of their relation of reference to the world. ${ }^{1}$ This burdens pragmatists with the task of providing a practice-based explanation of how participants might individually and collectively be wrong about the meaning and application of concepts, or of how we can do without the idea that they could. At the socio-political level, pragmatist approaches to normativity face a parallel challenge: it seems that the primacy of practice renders them incapable of providing a standpoint for criticism, apparently committing theorists to a kind of social positivism or conventionalism that is forced to accept existing practices as authoritative.

My aim in this paper is to examine a particular kind of pragmatism, developed by Robert Brandom, and to show that it has resources for addressing this concern at the socio-political level that have so far not been acknowledged. The central aim of Brandom's Making It Explicit is to provide an explication of the normativity of meaning in terms of social practice, including a social-pragmatic account of conceptual reference and objectivity which makes intelligible that a linguistic community can be held to be mistaken about the proper meaning and application of concepts. The debate on Brandom's social pragmatism has focused on this theory of meaning and its implications for philosophy of mind and action; its uptake in social and political philosophy has so far been very limited. ${ }^{2}$ Yet, as I aim to show, Brandom's theoretical framework also provides fertile soil for a social-pragmatic approach to social and political philosophy that is neither necessarily positivist nor conservative. To see this, we 
need to delve into his controversial account of conceptual normativity and bring out its essentially contestatory character-which has not been sufficiently appreciated by either Brandom or his critics. Doing so should clear a hurdle for the fruitful appropriation of this agonistic social pragmatism for social and political philosophy.

Brandom has developed a sophisticated and systematic theory of meaning in terms of use, which I introduce in more detail in section two. He argues that concepts have their point and purpose in social practices that are implicitly normative. In Brandom's vocabulary, participants in social practices are interpreted as engaged in 'deontic scorekeeping', where each keeps multiple sets of books that track the commitments and entitlements of others and themselves. Commitment and entitlement are the basic normative statuses that participants attribute to one another; they are what one might call the currency of social practice. From each participant's perspective, the significance of a commitment is assessed against a repertoire of further commitments. Such repertoires of background commitments are embodied in social practices in the widest sense, in habits, institutions, ways of speaking, etc. Much of individuals' mutually holding each other to account is a matter of implicitly treating one another as committed to do and to believe various things in social practices. While these normative statuses can often be made explicit and disputed in a game of giving and asking for reasons, Brandom holds that they cannot be explained with reference to explicit rules or principles, but should be understood in first instance as implicit in the actions and attitudes of participants. For him, the pragmatist idea of the primacy of practice takes the form of the claim that normative statuses are 'instituted' by social practices, or more precisely, by the scorekeeping activity or practical attitudes of individuals; what it is for something to be appropriate is understood in terms of what it is for something to be taken to be appropriate.

Yet, as many commentators have pointed out, it is difficult to see the exact sense in which, according to Brandom's theoretical framework, normative statuses are instituted by social practices (or the attitudes of participants engaged in them). ${ }^{3}$ While he repeatedly states that 
normative statuses are to be explained in terms of practical attitudes, Brandom holds at the same time that social practice is irreducibly normative: normative statuses are invoked again to explain the notion of practical attitudes, and so his approach appears circular at best. In section three, I present a reading of Brandom's account of normativity that tries to make sense of the complex relation between normative statuses and practical attitudes by emphasizing the contestatory character of social practice. Social practice, as an ongoing open-ended process of action and response, should be understood not just as a form of cooperation, in the sense that individuals are engaged in a common activity, but also as a form of contestation, where social perspectives inevitably conflict. My interpretive claim is that due to its perspectival, dynamic, and open-ended character, Brandom's view of social practice can fruitfully be understood as an 'agon'; a continuous contest — not a struggle for annihilation —in which the standards of excellence are themselves also object of contestation. This does not mean that social practice is irrational or a mere play of power-relations. It does mean it involves contestation all the way down. ${ }^{4}$ There is no sovereign perspective according to which truth and appearance can be distinguished, or criteria formulated for distinguishing them - there are only the situated social perspectives of actual participants, which always to some extent differ and conflictand it is precisely this difference that keeps the practice going. Seen through the lens of the agon, the socio-perspectival distinction between normative statuses and practical attitudes expresses a tension between merely acknowledged and actually undertaken commitments that is inherent in social engagement. This suggests that talk of 'institution' of normative statuses by normative attitudes is slightly misleading; rather, normative statuses are brought into play in mutual engagement, and are only in play from an engaged social perspective.

This contestatory character of conceptual normativity is also the key to addressing the charge of positivism or conventionalism at the socio-political level. The absence of a privileged or sovereign standpoint does not imply the absence of a standpoint of critique. Against a positivist reading of Brandom, put forward by Robert Pippin, and against the grain 
of some of Brandom's own formulations, I argue in section four that the possibility of a critical stance toward social practices is not only compatible with but already implicit in his agonistic form of social pragmatism. I make this explicit with the notion of farcical practices: practices that are treated merely as if they institute genuine commitments and entitlements, although - according to some interpretation of the practice within a wider constellation of social practices - those commitments and entitlements are disingenuous or illegitimate. ${ }^{5}$ Interpreting a practice as farcical is taking a critical stance toward it, and the possibility of articulating this is inherent in Brandom's theoretical framework.

\section{The pragmatic turn}

Brandom presents the vast theoretical edifice of Making It Explicit as an expression or articulation of what people do when they talk and think-its aim is to 'mak[e] explicit the implicit structure characteristic of discursive practice as such' (Brandom 1994: 649). This expressive project enables us to see how meaning and intentionality can be explained in terms of the roles that concepts, propositions, beliefs and actions play in social practices. The meaning of an expression cannot be explained independently of an account of its use; conceptual content is conferred upon linguistic expressions and actions by discursive practices. Brandom aims to show how this works by providing a theory of meaning (semantics) rooted in a theory of use (pragmatics). In his view, one can make meaning and intentionality intelligible by showing how they are bound up in practices; one cannot make those practices intelligible by reference to a prior notion of conceptual content-a commitment nicely summed up in the maxim: 'semantics must answer to pragmatics' (Brandom, 1994: 83, 145). This situates Brandom in a broad pragmatist tradition that views meaning in terms of use (of which the later Wittgenstein is probably the most famous 
exponent) - but the extent to which Brandom systematically theoretically elaborates this idea is unprecedented.

Brandom sees this approach as reversing the order of explanation adopted by a more established approach based on the notion of representation (Brandom 2001: 4). ${ }^{6}$ On that approach, for linguistic expressions to have meaning is for them to represent something about the world. In virtue of that relation to the world, conceptual content can be believed and expressed by individuals. The relation of representation thus provides the basis for explaining the functions that beliefs and assertions can perform for agents who encounter one another in a shared world. Brandom does not deny that expressions can represent something about the world; what he denies is that this relation is a good starting point for an explanation of meaning and intentionality. More specifically, it does not provide resources to analyze the dualistic relations between mind and world or subject and object it postulates. ${ }^{7}$ Brandom claims that if one starts instead with the role conceptual contents play in social practice, their representational aspect can be made intelligible as implicit in social practice. Meaning is conferred upon beliefs and assertions by our ways of using them, rather than by a relation to the world that can be antecedently specified. So meaning is in first instance expressive rather than representational (Brandom 2001: 7-10). To assert something is to do something, to participate in a 'game of giving and asking for reasons' (Brandom 1994: 167). To show how this sense of expression can explain a notion of representation - that beliefs or assertions can be about the world — is one of the main tasks he sets for himself.

As I mentioned, the idea of a primacy of practice is not new, but Brandom develops it in systematic and innovative ways. What marks his distinct flavor of pragmatism is to begin with his way of explaining the content of concepts in terms of their role in reasoning - his pragmatism is a form of rationalism. It is also a social pragmatism, because he sees reasoning as a social activity, a game of giving and asking for reasons. ${ }^{8}$ One of his most original views is that the representational dimension of concepts - the capacity of beliefs and assertions to be 
about the world - is a consequence of this social character of reasoning. The argument for this is complex and extends over the full length of Making It Explicit. But it is clear what he takes as his starting point: Brandom understands reasoning as intersubjective or dialogical, intelligible in first instance only in the context of interactions among participants in social practices. ${ }^{9}$ Moreover, reasoning is also a normative activity. Assertions can be challenged, reasons can be asked for, and these reasons can in turn be assessed as appropriate or inappropriate, correct or incorrect.

The centerpiece of Brandom's normative pragmatics (his theory of use) is a model that makes explicit in theoretical terms what participants are doing when they engage in discursive practice (the game of giving and asking for reasons), which he calls 'deontic scorekeeping'. Discursive practice is a particular kind of social practice in which participants say things, or in Brandom's terms, in which certain performances count as assertions. ${ }^{10}$ Social practice in general is irreducibly normative; social practices (and therefore discursive practices) essentially involve 'proprieties of performance' (Brandom 1994: 159). Participants do not merely exhibit regular patterns of behavior; they issue performances that are appropriate or inappropriate according to the practice. Importantly, this does not mean that all social practices are to be understood with respect to explicit rules or principles; more often this normativity is implicit in the ways participants treat each other, in the attitudes they adopt and the stances they take. Accordingly, he distinguishes between two kinds of norms: explicit rules or principles, and implicit proprieties of practice. ${ }^{11}$ The idiom of 'deontic scorekeeping' aims to make the implicit normativity of discursive practice explicit. In explaining Brandom's notion of scorekeeping, let me highlight some crucial features of this view of discursive practice: its normativity; its socio-perspectival character; its dynamism; semantic inferentialism; and finally, the interpretive character of the theory itself.

The irreducible normativity of discursive practice (and social practice more generally) is reflected in the basic vocabulary Brandom deploys in explicating it: the notions of 
commitment and entitlement. Commitment and entitlement are what he calls normative or deontic statuses: a commitment obliges or makes one responsible to do something in the eyes of the one attributing it, and an entitlement authorizes or licenses one to do something, again in the eyes of someone (another participant, or an interpreter, or oneself). These normative statuses are the basic currency of social practice: participants keep track of their own and others' commitments and entitlements — what each is required or authorized to do, believe, intend, etc.- - in a game of deontic scorekeeping (Brandom 1994: 180-191). Normative statuses are socially attributed; scorekeeping is a matter of adopting practical attitudes toward one another, taking performances to be appropriate or inappropriate, that is, attributing or withholding commitments and entitlements (with whatever practical consequences that entails in the situation). Discursive practices are normative, then, in the sense that they are practices of mutually holding one another to account.

Scorekeeping is a socio-perspectival activity: each participant keeps track of the normative scores from his or her own socially situated viewpoint. Scorekeepers don't just adopt these practical attitudes toward others but also toward themselves. Participants take each other to have different repertoires of commitments and entitlements; each scorekeeper keeps multiple 'sets of books' to track and distinguish between the commitments and entitlements of him- or herself, and those of other participants (Brandom 1994: 488, 590). This allows Brandom to distinguish between the different attitudes of attributing, undertaking, and acknowledging a commitment. Attributing a commitment is the practical attitude of taking someone to be committed to something. Acknowledging a commitment is attributing it to oneself, taking oneself to be committed. And for someone to undertake a commitment is to do something that entitles others to attribute the commitment to that person (Brandom 1994: 162). This means that one can undertake a commitment (according to someone else) without acknowledging it. The game of giving and asking for reasons is the practice whereby participants negotiate these differences of perspective, mutually evaluating what each says and does against a background 
of further commitments. From a listener's perspective, whether a speaker is entitled to a claim is assessed in light of its compatibility with other commitments the listener takes the speaker to be committed to. At the same time, the listener assesses what the speaker says in light of her own commitments to determine whether it is something to which she is willing to acknowledge commitment herself.

Deontic scorekeeping is a dynamic activity in the sense that participants not only keep track of one another's scores (in normal language: beliefs and their truth, intentions and their propriety), they also engage one another with words and deeds, trying to alter the score. Attributions of commitments and entitlements are continually adjusted in light of what participants say and do, and this is what gives words and deeds their significance. In Brandom's vocabulary, performances have 'pragmatic significance' insofar as they alter the patterns of commitments and entitlements participants undertake and attribute: 'The significance of a performance is the difference it makes in the deontic score - that is, the way in which it changes what commitments and entitlements the practitioners, including the performer, attribute to each other and acquire, acknowledge, or undertake themselves' (Brandom 1994: 166). So discursive practice is a dynamic process of ongoing mutual engagement.

Consider the speech act of making a claim or assertion, which is central to Brandom's notion of discursive practice. He asks: "What is it we are doing when we assert, claim, or declare something?' (Brandom 1994: 167) Part of the answer is that we undertake a certain kind of commitment, a 'doxastic commitment' or belief. In making a claim, a speaker commits herself to what she says. If a listener understands the speaker, he takes her to believe what she says - he attributes a commitment to her — and he can furthermore assess whether or not she is entitled to undertake this commitment, that is, if it is compatible with the other commitments he attributes to her. From the perspective of the speaker, her assertion entitles the listener to acknowledge commitment to what she said. Here 'what she said' refers to the 
conceptual content or meaning she expresses. The important question for understanding meaning in terms of use is: How is this conceptual content to be understood in terms of what is done? What makes an assertion meaningful, and how can assertions be compatible or incompatible?

The answer is what Brandom calls 'semantic inferentialism' (Brandom 1994: 67-140; Brandom 2001). ${ }^{12}$ On this view, the content of an expression consists in its relations to other expressions. Meaning is relational, and the relation that gives content to an expression is not one of reference between an expression and something in the world, but of inference between an expression and other expressions. They stand in such relations in the first place in virtue of being used in practices of reasoning, by counting in practice as premises and conclusions for other expressions. To take an assertion to mean something is to treat it a certain way: to take certain propositions to follow from it and others to count as reasons for or against it. Grasping a concept is mastering its inferential circumstances and consequences of application, that is, being able to tell what else a speaker commits herself to by invoking a particular concept in a particular situation. Semantic inferentialism implies a holistic view of meaning, because concepts have their content only with respect to other concepts; one can only have one concept if one has many. Consequently, committing oneself to one thing is committing oneself to a lot of other things as well. This inferential articulation of commitments has an important consequence, when it is combined with the idea that participants have the practical ability to distinguish between their own and others' commitments: the commitments one has undertaken outstrip those one acknowledges. As Brandom states: 'The crucial inferential articulation of discursive commitments consists in part in the fact that unacknowledged commitments can be (taken by other scorekeepers to be) undertaken consequentially, by acknowledging commitments to claims that (according to those scorekeepers) entail them' (Brandom 1994: 627). 
Semantic inferentialism should not be mistaken for a formalistic or disembodied account of meaning. ${ }^{13}$ The inferential relations between concepts are constituted in actual, day-to-day social practices. Brandom provides accounts of the role of perception and action in these practices, which connect concepts to the world and objects in it. In virtue of these practices, the basic sense of compatibility between conceptual contents is one of material rather than formal compatibility. For material inferences, the contents of the premises and conclusion, rather than the logical form of the inference, determine whether the inference is a good one. Examples Brandom gives are the inference from 'today is Wednesday' to 'tomorrow will be Thursday' and from 'lightning is seen now' to 'thunder will be heard soon'. 'Endorsing these inferences is part of grasping or mastering those concepts, quite apart from any specifically logical competence' (Brandom 1994: 98). Brandom gives priority to material over formal inferences, arguing that the latter can be explained in terms of the former (Brandom 1994: 97107; cf. Sellars, 1953).

A final feature of Brandom's pragmatism that is important to mention is that it is interpretive all the way down. To take someone's assertion as meaningful is to take a stance toward her, treating her as a participant on whom score can be kept, and holding her responsible for living up to her commitments and answerable to challenges to her entitlement to those commitments. Similarly, in taking participants in social practice to be deontic scorekeepers, an interpreter adopts a scorekeeping perspective toward them. 'In adopting such a stance, the interpreter takes the interlocutors being interpreted to be committed to keeping score according to specific patterns' (Brandom 1994: 638). Participants are engaged in social practices; objects are merely involved in them. To take a pile of bricks to be inanimate objects merely involved but not engaged in a practice (say, bricklaying), is to take a different kind of stance toward them: to take it that certain things can be true or false of them (for instance, that they are brown and suitable for constructing a wall), but that they cannot be committed or entitled to anything. This is not to say that bricks cannot be taken to be engaged in practices 
(we can imagine some form of ritualistic practice, for instance, in which participants attribute beliefs or intentions to bricks), but that whether they are or not is in some sense a normative matter, which depends on whether or not it is appropriate, according to an interpretation of the relevant practice, to treat them as participants (cf. Brandom 1979). So there is an important parallel between what a participant in social practice is doing and what a theorist or interpreter of social practice is doing:

$[\mathrm{O}]$ nce the task of external interpretation is recognized as a special case of internal interpretation (scorekeeping), the practical norms that govern the attribution of one set of conceptually contentful commitments rather than another can be recognized as just one more instance of deciding what others of us are talking about and what they are saying about it. (Brandom 1994: 647)

In short, Brandom interprets social practice as a matter of participants' mutually holding one another to account, from each participant's socially situated perspective, in ongoing dynamic engagement. In discursive practice, this implicit deontic scorekeeping is made explicit by giving and asking for reasons.

\section{Normativity and the agonal character of discursive practice}

The deontic scorekeeping model just described invokes normative statuses (basically, commitment and entitlement) and practical attitudes (taking someone to be committed or entitled) to articulate what goes on in discursive practices. But where do these normative statuses come from? On the one hand, the direction of explanation for a pragmatist, Brandom tells us repeatedly, is from an account of what it is to take something to be true, meaningful or correct, to an account of what it is for something to be true, meaningful or correct-from attitudes to statuses. This may give the impression of an unconstrained subjectivism or relativism, where what is true or what counts as knowledge is entirely up to subjects 
themselves. On the other hand, however, his deontic scorekeeping model invokes normative statuses as basic and irreducible. How can normative statuses on the one hand be understood as implicit in practices, or as Brandom also tends to put it, as 'instituted' by those practices, and yet at the same time be genuinely binding, independently of the actual attitudes of participants? We need to get a better view of the complex relation between practical attitudes and normative statuses. It is worth noting that a version of this question is likely to arise for any pragmatist account of normativity, and it has been a central issue for Brandom's critics and commentators. ${ }^{14}$ In my view, it can only be clarified by stressing the contestatory aspect of this social pragmatism - which is not sufficiently acknowledged and emphasized, including by Brandom himself. Bringing this aspect forward will also help to explain in the next section why this account of normativity in terms of social practice does not commit us to a kind of social positivism.

First let me clarify the problem. Brandom maintains that normativity is 'instituted' by social activity. ${ }^{15}$ Normative statuses arise from and cannot be understood apart of the scorekeeping activity (stance-taking) of participants. Scorekeeping is understood in terms of practical attitudes - attitudes of taking one another to be committed and entitled to various things. Yet at the same time, normative statuses must be in some sense independent of the practical attitudes that participants actually adopt. Normative statuses cannot collapse into practical attitudes without forfeiting their claim to be genuinely binding. Communication becomes impossible if the meaning of an expression is entirely up to each speaker or listener. So whether a particular attribution of a normative status is appropriate cannot simply be up to the participant. Hence, Brandom emphasizes, 'the distinction between status and assessment (the attitude of taking or treating a performance as correct, appropriate, or in order) is essential to the notion of genuinely normative status' (Brandom 1994: 52). A central aim of Brandom's project, then, is to account for this peculiar relation between practical attitudes and normative statuses - 'between what someone is really committed or entitled to and what 
anyone, including even the subject of those statuses, takes that individual to be committed or entitled to' (Brandom 1994: 497). So it is important to distinguish clearly between the attribution of normative statuses, which is the adoption of practical attitudes, and the institution of normative statuses, which is somehow a product of the adoption of practical attitudes, but not reducible to it. The difficulty is in understanding how exactly this notion that social practices 'institute' normative statuses is to be cashed out without collapsing normative statuses into practical attitudes.

A useful place to begin to explain this is to ask the question whose attitudes are supposed to institute normative statuses. Initially two options seem available, but both turn out to be problematic (Brandom 1994: 52-55). On the one hand, one can construe normative statuses as instituted by the attitudes of individuals. But this collapses a normative status into a practical attitude — something's being correct into its being taken to be correct—since there would be no sense in which an individual's assessment of commitments and entitlements could be mistaken. This is the pitfall of subjectivism. On the other hand, the distinction between a (instituted) normative status and an (attributed) individual assessment of it could be preserved by treating the attitudes of a community as a whole as authoritative. Someone's takingsomething-to-be-correct could be held answerable to something's being-correct-according-tothe-community. But this makes the possibility that a whole community could be wrong unintelligible and invokes a reified conception of community. This is the pitfall of communal assessment (Brandom 1994: 37-41).

Brandom's provocative idea is that it is precisely the perspectival character of social practice that makes sense of the relation between normative statuses and practical attitudes. Normative statuses (such as commitments and entitlements) are 'instituted by constellations of socially perspectival normative attitudes of attributing and undertaking such commitments' (Brandom 1994: 62). The crux is to focus not on the relation between the individual and the community, but on the differences of social perspective between participants engaged in 
discursive practice. How does this work? As we've seen, participants attribute meaning to expressions against the background of their own wider commitments - something means to them what they take it to mean - and as a consequence the same assertion can mean slightly (and sometimes widely) different things to different people:

The semantic contents of discursive commitments, attitudes toward those commitments, and the linguistic performances that express those attitudes can in principle only be specified from the perspective provided by some repertoire of background commitments and attitudes; how it is correct to specify any particular content varies from one such repertoire to another. (Brandom 1994: 497, cf. 586-592)

Recall that the content of an expression is to be understood in terms of its inferential relations to other expressions, what it counts as a premise or a conclusion for. Given that individuals have different repertoires of commitments, these inferential relations are different for every scorekeeper. In order to take assertions to be meaningful and (potentially) true or correct at all, participants must be able to distinguish in practice between the significance an expression has from their own point of view and from that of others- between the consequences others take an expression to have, and those one endorses. The expression, 'According to $A$ Theory of Justice, justice is the first virtue of social institutions', licenses various inferences depending on the further commitments of whoever endorses it. For instance, only to someone who knows that John Rawls was the author of the book A Theory of Justice, does it imply that 'John Rawls thought that justice is the first virtue of social institutions'. According to Brandom, the ability to communicate is a matter of mastering the navigation of these differences of perspective - the capacity to assess what an assertion implies with respect to different repertoires of commitments and entitlements. 'Carrying on a conversation involves being able to move from perspective to perspective, appreciating the significance a remark would have for various interlocutors' (Brandom 1994: 635). 
Brandom provides detailed analyses of the language that facilitates the expression and navigation of these differences of social perspective. For instance, he explains in deontic scorekeeping terms how singular terms purport to refer to objects (Brandom 1994: 334-403), and how different linguistic expressions can have the same semantic content (for instance how anaphora pick up the content of an expression while substituting a different expression, so that, say, 'he' can in certain circumstances be substituted for 'John Rawls') (Brandom 1994: 404-489). Implicit in these ways of speaking, he claims, is the representational dimension of meaning. By using representational expressions - speaking of or about certain thingsparticipants purport to talk about and dispute the same things, while understanding them differently. What is important for Brandom is that this representational dimension, while already implicit in discursive practice from the start, can be elucidated in inferential and pragmatic terms without appealing to a prior representational relation to the world. This is how Brandom makes good on his commitment of explaining representation in terms of discursive practice, rather than the other way around.

The details of this argument are beyond the scope of this paper, but it is helpful to briefly discuss the distinction between de re and de dicto ascriptions of meaning, which is central to Brandom's account. De re and de dicto ascriptions enable participants to distinguish between the different meaning (or inferential significance) statements have for different interlocutors. For instance, suppose someone were to say: 'According to the author of the assigned reading, justice is the first virtue of social institutions'. A listener might now acknowledge commitment to the effect that the assigned reading was the beginning of $A$ Theory of Justice by John Rawls. According to the listener, the speaker believes that the assigned reading stated that justice is the first virtue of social institutions, and thereby believes of John Rawls that he thought that justice is the first virtue of social institutions, even if he (the listener) takes it that the speaker does not know who the author of the assigned reading is. The listener can report the original statement to a third person in terms that the original speaker would acknowledge, 
that is, de dicto: 'She said that the author of the assigned readings claims that justice is the first virtue of social institutions'; or in terms that he himself endorses, de re: 'She said of John Rawls that he claimed that justice is the first virtue of social institutions'. In this way, interlocutors can distinguish between the different perspectives from which an expression is understood. Words like 'that' on the one hand, and 'of' and 'about' on the other can help to distinguish explicitly between what someone is talking about, what he says about it, and how what he is talking about should actually be understood. So Brandom argues that rather than locking participants in their own perspectives, consigned to talking past each other, the mutual engagement of these different perspectives in conversation and dispute enables them to talk about the same things from different points of view:

It is the different perspectives provided by different sets of commitments that make it possible to triangulate on objective states of affairs. Our practices of comparing, assessing, and correcting different repertoires of commitments one with respect to another-those we attribute to others and those we undertake ourselves - are what make them intelligible as perspectives, views of something, ways in which a perspective-independent reality can appear. (Brandom 1995: 907)

Mutually holding one another to account in this way also involves holding oneself responsible, because such engagement also gives rise to the need for self-interpretation and hence self-criticism. Distinguishing the commitments and entitlements of others from one's own involves taking others to be correct or mistaken in light of the commitments one is willing to undertake oneself, that is, in light of what the world is really like or what people have actually done, according to the scorekeeper. But assessing others' commitments in practice involves also giving one's own commitments up for assessment, acknowledging the possibility that one might need to revise them. Undertaking a commitment involves a responsibility to provide reasons for it when challenged, and revising one's repertoire of 
commitments if better reasons are put forward. Each participant, therefore, not only distinguishes between commitments attributed to others and those undertaken by himself, but also between the commitments he acknowledges and whichever commitments it would be appropriate to undertake. This distinction arises in virtue of the fact that scorekeeping is an engagement between a multiplicity of perspectives.

This social-perspectival structure of discursive practice makes it possible to explicate the distinction between normative statuses and practical attitudes without collapsing one into the other. The notion of a normative status expresses the difference from a scorekeeping perspective between commitments one attributes to others and those one is willing to acknowledge, or, with respect to one's own commitments, between those with which one happens to find oneself and those one should endorse. This possibility of being mistaken —in particular cases, as there is of course no point of view from which one can assess one's repertoire of commitments as a whole-is an inherent or structural feature of scorekeeping. This is what the notion of the 'institution of normative statuses' makes explicit: 'This perspectival structure is what has been implicitly appealed to throughout by talk of the institution of deontic statuses by deontic attitudes' (Brandom 1994: 597).

Speaking of the 'institution' of normative statuses may invite an interpretation according to which there is some sovereign perspective - the definitively instituted scorecard, specifying the way the world really is independently of a socially situated perspective- - with which one might compare the scores actually being kept by participants. And this impression might be reinforced by Brandom's insistence that this social-perspectival account of meaning makes available a notion of objectivity, which consists in the possibility that not only each individual, but everyone can be mistaken about the truth of an assertion or the application of a concept. ${ }^{16}$ But it would be a mistake to understand Brandom that way. Normative statuses are instituted by scorekeeping activity just in the sense that distinguishing between normative statuses and practical attitudes is something done from each perspective. In fact, Brandom's 
account of discursive practice is radically anti-sovereign - there is no correctness aside from a perpetual struggle to determine, always provisionally, what counts as correct:

[E]ach perspective is at most locally privileged in that it incorporates a structural distinction between objectively correct applications of concepts and applications that are merely subjectively taken to be correct. But none of these perspectives is privileged in advance over any other. [...] What is shared by all discursive perspectives is that there is a difference between what is objectively correct in the way of concept application and what is merely taken to be so, not what it is - the structure, not the content. (Brandom 1994: 600)

So the scorekeeping account of discursive practices does not provide resources for designating particular assertions as objectively true or determining what concepts really mean. The notion of objectivity appears deflated; it turns out that, after all, 'there is never any final answer to what is correct' (Brandom 1994: 647). There is no neutral ground between perspectives, nor a standpoint above from which to adjudicate among them; only from a situated perspective, among others, engaged in practice, is there a distinction between what is true and false, appropriate and inappropriate. Social perspectivism implies not that we should give up the notions of truth and normative constraint, but that we should give up the aspiration to an a-perspectival standpoint or view from nowhere, not engaged in and bound by social practice. As Brandom puts it:

Sorting out who should be counted as correct, whose claims and applications of concepts should be treated as authoritative, is a messy retail business of assessing the comparative authority of competing evidential and inferential claims. [...] There is only the actual practice of sorting out who has the better reason in particular cases. The social metaphysics of claim-making settles what it means for a claim to be true by settling what one is doing in taking it to be true. It does not settle which claims are true- that is, are correctly taken to 
be true. That issue is adjudicated differently from different points of view, and although these are not all of equal worth there is no bird's-eye view above the fray of competing claims from which those that deserve to prevail can be identified nor from which even necessary and sufficient conditions for such deserts can be formulated. The status of any such principles as probative is always itself at issue in the same way as the status of any particular factual claim. (Brandom 1994: 601; last emphasis added)

On my reading, the institution of normative statuses by social practices or the practical attitudes of those involved in them should not be understood in a static way, as if there were an initial act of 'making' that first brought the status into being so that subsequently it is simply there, for participants to answer to. There is strictly speaking no act of institution at all; it is in the activity of scorekeeping, rather than by means of that activity, that normative statuses are instituted, and hence that participants are accountable, responsible, committed and entitled to various things. Perhaps it is better to say, therefore, that normative statuses come into play in social practices, holding participants in their thrall (cf. Gadamer 2004: 102-106).

Putting the point in this way reveals a deeply agonal aspect of Brandom's thought. The notion of the 'agon', which means contest or struggle, has its origin in ancient Greece, where contestation had a central role in many areas of social life. ${ }^{17}$ As I understand this notion, agonal contestation involves a plurality of contestants continually striving for excellence-or rather, whatever counts as excellence according to the practice, according to the participants-while mutually holding one another within bounds of measure. Agonal contestation is inherently repeatable and open-ended; a definitive victory of one participant would be the end of the practice. Discursive practice is similarly open-ended and relies on multiplicity and difference in perspective. Crucially, measure in the agon, and normative constraint in Brandom's account of discursive practice, is not something imposed from without, nor a product of the subjective intentions of the participants, but arises from the dynamics of their interaction (cf. Siemens 2002: 102-106). In the agon, what counts as 
excellence is not fixed in advance, but is also object of contestation, determined provisionally through the ongoing engagement of participants. Just so, in discursive practice, what is true, correct, or meaningful cannot be determined in advance of the practice, nor can it be identified with any individual subject's assessment of it or with that of the community as a whole. Rather, it is a function of the engagement, as assessed from each perspective. This point is reflected in Brandom's remark, in the quote above, that the status of criteria for what counts as true or appropriate is 'always itself at issue'. So this agonal aspect runs all the way down and is irreducible.

Seen through the lens of the agon, the socio-perspectival distinction between normative statuses and practical attitudes expresses a tension that is inherent in play. As a dynamic and ongoing engagement, discursive practice is characterized by a constitutive tension between acknowledged and actually undertaken commitments. What participants are really committed to is always to be determined in practice and therefore always in some sense underdetermined. Discursive practice (reasoning) is not out to dissolve this tension; as a practice it relies on it. Plurality and disagreement are not defects, but the source of the productivity of agonal engagement or discursive practice. On the one hand, it is productive in the sense of opening up a common world; for Brandom, there is no common world except through plural perspectives on it. ${ }^{18}$ Only as engaged in activity with others does the possibility of being mistaken oneself become intelligible, because only then does one's perspective appear as a perspective. On the other hand, it is productive in the sense that discursive scorekeepers or agonal contestants develop new ways of speaking and acting and are transformed through their engagement. To engage discursively is also to open oneself up to criticism, and thereby to self-transformation (cf. Owen 1995: 142-144, 160). This implicit commitment to selfovercoming is reflected in Brandom's view that the task of philosophy is to

com[e] up with new, ever-more-interesting [...] vocabularies as candidates to identify with, as expressive tools allowing us to take ourselves to be new kinds of being, and so to make 
ourselves into something new and different, preserving and accumulating previously disclosed possibilities and projects while transforming and adding to them. (Brandom 2009: 155)

Brandom underplays the agonal character of his theory when he describes discursive practice as a cooperative endeavor while ignoring its element of contestation. ${ }^{19}$ Discursive practice is not just cooperative, but also contestatory: participants try to redeem their own claims, get others to subscribe to their own standards for what counts as true and correct. In a recent article, Brandom gives an instructive example. He likens his view of discursive practice to a dance:

Practitioners who understand each other in this practical sense-who can successfully make use of each other's remarks in their own reasoning, both about what the other has reason to do (given his or her beliefs) and about what one has oneself reason to do (given one's own beliefs) — do indeed 'share' something. But what they share is like the dance that Fred and Ginger are doing together-one and the same dance, even though individually they are doing different things. [...] We can think of conceptual [...] content as like Fred and Ginger's dance: something that is essentially perspectival, in that grasping it (like engaging in the dance) requires doing different things from each individual participating (in the conceptual case, depending on the background constituted by their other commitments). (Brandom 2007: 668)

The example of a dance nicely captures the dynamic, performative aspects of discursive practice, where participants share their being engaged in an activity, but not their actions or even their understanding of that activity. But if we push this example a little further, taking a slightly broader view of the practice, where others are involved as well, as performers or as audience, we cannot avoid elements of contestation. What marks a dance as a dance are certain norms or standards of excellence. The joy of dancing lies in part in a striving for 
excellence, and potentially in outshining others. But excellence in dancing isn't just conforming to antecedently specified norms, making exactly the right steps at the right time. Excellent dancers can change the dance in process, make it their own, invent new moves and even new styles of dancing. What counts as a dance-move displaying a particular excellence and what as a misstep isn't fully specifiable in advance but depends also on its uptake in subsequent activity. ${ }^{20}$

This agonal character is an essential but underappreciated feature of Brandom's understanding of discursive practice. I think it is essential, because his account of normative constraint in terms of the distinction between normative statuses and practical attitudes cannot be properly understood without it. Precisely this agonal aspect of his thought enables Brandom to avoid the pitfalls of subjectivism and communal assessment. Instead of collapsing the distinction between normative statuses and practical attitudes at the individual or communal level, the distinction should be seen as a tension inherent in mutual engagement and contestation. It is underappreciated also because it shows that Brandom's social pragmatism is not committed to a kind of social positivism. To this I now turn.

\section{Farcical practices}

Having emphasized the agonal or contestatory character of Brandom's account of meaning in terms of use, it is now possible to address the issue of its alleged social positivism or conventionalism: the idea that this approach resigns theorists (as interpreters) to describing practices, forcing us to accept as normatively binding the practices and institutions with which we find ourselves (or which we ascribe to a community), denying the possibility of social criticism (see, for instance, Pippin 2005: 395-396; Pinkard 2007: 164-166). Although a few of Brandom's explicit statements give some ground for attributing a social positivism to him, the 
agonal aspect of his social pragmatism shows that he cannot really be committed to this and that the possibility of a critical stance is built in from the start.

The prima facie appeal of this charge lies in the suggestion that if normative statuses come into play only through social practices, those normative statuses cannot provide critical purchase on those same social practices. An obvious response, to which I take Brandom to be in fact committed, is to say that social practices do not take place in a vacuum, but rather come in constellations of interconnected practices; that these practices and their interconnections are all subject to interpretation and hence contestable; and that even though they cannot all be criticized at the same time (if only because criticizing is itself a practice), in practice there is always some standpoint from within from which another point can be subjected to criticism. ${ }^{21}$

Yet it is worth examining the textual basis for attributing a social conventionalism to Brandom a bit more closely. He does make some apolitical gestures that seem to deny the possibility of social criticism. Brandom says, for instance, that there are certain norms about which a community as a whole cannot be mistaken. The idea is that some norms are just conventions, such that whatever a community takes to be the norm, is the norm. Examples Brandom gives include what the Kwakiutl (a Native American tribe) take to be appropriate greeting gestures, and 'who is really married' in a particular community: 'it makes no sense to suppose that they could collectively be wrong about this sort of thing' (Brandom 1994: 5354). He contrasts such apparently unproblematic social conventions with discursive norms (concepts), the normativity of which calls for further explanation (which is the task of Making It Explicit). In these cases, it seems, Brandom does not object to collapsing normative statuses into communal practical attitudes: 'The community is incorrigible [in such cases] about what is a proper application of a concept and what is not' (Brandom 1994: 53).

These remarks on social conventions are a bit too simplistic for several reasons. For a start, greeting gestures and who appropriately counts as married are not things one cannot 
intelligibly hold a community to account for. When and whom it is appropriate to greet in what way under certain circumstances can easily become a matter of dispute; greetings are often tailored to positions in a social hierarchy, for example. And the idea that a community cannot intelligibly be taken to be wrong about who appropriately counts as married seems to be invalidated by controversy over gay marriage. Brandom's use of these examples only works on the assumption of a mythically homogeneous community where there is no disagreement on these issues. But these remarks are puzzling also in light of more theoretical reasons, because a few pages earlier, Brandom criticized the idea of communal assessment as a basis for normativity - that norms are to be understood in terms of the attitudes of a community: '[T]he idea of communal performances, assessments or verdicts on which it relies is a fiction. [...] Assenting, endorsing, accepting, and regarding as right are in the first instance things done by individuals' (Brandom 1994: 37). Intersubjectivity should be understood in terms of the relations between individuals, not in terms of the relation between individual and community; Brandom calls this an 'I-thou' rather than 'I-we' construal of intersubjectivity (Brandom 1994: 39). In light of this fundamental criticism, it seems strange that Brandom grants that for certain norms the communal assessment analysis is correct: the 'community's all-inclusive practical assessment cannot be mistaken' (Brandom 1994: 54). Brandom can address this by suggesting that a community can have certain practices that determine what is to count as the communal view, even given disagreement about the matter: 'Some communities have meetings, authorized representatives, or her ways of officially settling on a communal view or act [...]' (Brandom 1994: 38). But that would render the idea that the community cannot be held to account on certain matters more plausible only if the propriety of such procedures were uncontestable.

The idea that there are certain norms about which a community cannot be mistaken derives its appeal from the notion that some things are simply a matter of convention, whereas other norms are such that even if everyone were to agree, they could still be mistaken. If everyone 
takes it that raising one's right hand is an appropriate greeting gesture in certain circumstances, it just is, whereas everyone may take it that the earth is flat, even if in fact it is not. The sign is arbitrary in a sense in which a belief is not; for this the community is not answerable to anything, whereas beliefs about the world are answerable to the world. But it does not follow that conventions are therefore uncontestable, and a community is incorrigible about them. The key is to see that whether something is arbitrary, and therefore fully settled by mere convention, or objective, settled by the way the world is, is a normative question. It depends on a background of further commitments. Whether or not the earth is flat is not arbitrary in this sense due to a commitment to getting things right about the world (implicit, as Brandom argues, in discursive practice). Whether it is appropriate to raise one's right or one's left hand as a greeting is arbitrary only if we take it that the community is not already committed on the matter in virtue of some other consideration. To take something to be a matter about which the community cannot be mistaken, is to take it that there are no incompatible commitments on the matter, and hence to attribute an entitlement to the community to settle it in some way or other. So while the idea that a community is incorrigible on a certain matter may appear to collapse the tension between normative status and practical attitudes - and this is what fuels the charge of positivism - in fact it merely shifts this tension to the question whether the matter is arbitrary, or whether some other commitment is in place. This opens up any social convention to the potential critique that the matter at stake is not arbitrary, but harbors unacknowledged biases, reinforces certain relations of power, etc. In other words, the constitutive tension between actually undertaken and merely acknowledged commitments is kept in play, but shifted to a different register.

It is helpful to clarify the point with another example. In explaining what is involved in undertaking a commitment, Brandom puts forward by means of illustration a 'simplified and artificial version' of an eighteenth-century British practice of military recruitment. It is worth citing Brandom's description of the practice at some length. 
According to this practice, taking 'the queen's shilling' from a recruiting officer counts as committing the recipient to military service. A performance of this kind has the same significance that signing a contract would have - in either case one has joined the army and undertaken all the commitments entailed by that change of status. (The official rationale was that some such overt irrevocable nonlinguistic performance was required to do duty for signing a contract, given that those enlisting were largely illiterate. The actual function of the practice was to enable 'recruiting' by disguised officers, who frequented taverns and offered what was, unbeknownst to their victims, the queen's shilling, as a gesture of goodwill to those who had drunk up all of their own money. Those who accepted found out the significance of what they had done - the commitment they had undertaken, and so the alteration of their status - only upon awakening from the resulting stupor.) (Brandom 1994: 162)

Brandom deploys this example to illustrate what it is to undertake a commitment: 'The significance of a commitment is to be understood in terms of the practical attitude of those attributing it, that is in terms of what taking or treating someone as committed consists in'. (Brandom 1994: 162). The pragmatic significance of a performance is understood in terms of the difference it makes to attributions of commitments and entitlements:

The significance of taking the queen's shilling lies in its being an undertaking of a commitment on the part of the recipient, altering the attributions of commitment by those who appreciate the significance of the performance. It entitles other authorities - those who according to the antecedent score already had undertaken various commitments or duties and entitlements or sorts of authority, those who therefore play a certain role or hold a certain office in the system of practices in question - to punish the performer in particular ways under particular circumstances. The normative significances of performances and the 
deontic states of performers are instituted by the practice that consists in keeping score by adopting attitudes of attributing and acknowledging them. (Brandom 1994: 166)

One thing that is important about this passage is that it shows the sense in which what commitments one has undertaken is not simply up to oneself: unwittingly, one can take on a commitment and be held accountable to it, even though one has been duped into it. This makes it a provocative and perhaps counterintuitive example. Picking up on this, Robert Pippin critically interprets the passage as a prime example of Brandom's positivism:

I think most of us would say intuitively that the fact that others attributed such a commitment to an individual did not mean that that individual was, in normative fact, truly so committed, that the practice counted something as a commitment illegitimately, that it does not qualify as a commitment. But for Brandom, to undertake a commitment is just for an individual to do something that makes it appropriate for others to attribute a commitment to that individual, where 'appropriate' is a matter of a standing actual practice. [...] While Brandom sometimes gives the impression that the position defended in [Making It Explicit] just leaves open questions about genuine versus illusory claims to normative authority, I would say that it is quite clear that he has already taken positions on normativity, commitment, entitlement and obligation; the positions apparent in this passage. (Pippin 2005: 395-396; cf. Pinkard 2007: 164-166)

The position Pippin attributes to Brandom, I take it, is that actual practices just count. If you perform an action that a standing recruitment practice qualifies as signing up, you simply are recruited and answerable for the consequences. ${ }^{22}$ It is important to keep in mind, however, that the story about the queen's shilling serves as a 'simplified and artificial' expository device at an early stage in the elaboration of his theory. Brandom does not get back to this example later on, but a fuller story would have to take into account the features of deontic scorekeeping that he has not yet articulated at this stage, especially the socio-perspectival 
character of attributions of commitments and entitlements, and the idea that interpreting social practices is also a kind of scorekeeping practice.

In light of these features, the question whether some community is engaged in a practice, and what the norms are that are implicit in it, is itself a matter of interpretation; it is something that can be said only from a perspective (or rather: taking participants to be engaged in practice is having a perspective on them, keeping score); hence it is normative, something one can be held responsible for. There is no perspective-independent way practices are. This casts the example in a different light: the possibility of criticism is built in from the start. What a drunkard really commits himself to by taking the queen's shilling-what inferences this performance licenses-is assessed differently from different perspectives. Brandom suggests that, 'according to the practice', he commits himself to enlist. But we can draw up an alternative interpretation of the practice. For example, the situation may be such that none of the immediate participants - neither the poor drunk lad who is being set up, nor the recruitment officers - take unwittingly accepting the queen's shilling to be sufficient to enlist, even if they all keep up the pretense. (Of course, to interpret the situation this way, we'd have to be entitled to interpret them in this way in light of something they do, but imagine they secretly admit this to us.) They may all take it that punishment is likely to follow if he does not show up, but that leaves open the question whether the officials are entitled to punish, and whether he really is committed. The answer depends on an interpretation of the practice, in light of the 'antecedent score', as Brandom mentions, but this antecedent score is assessed differently from different perspectives, and presumably depends on a wide range of practices.

In real life, in contrast to Brandom's admittedly simplified and artificial example, what someone commits himself to by some behavior is always a matter of perspectival assessment. And in real life, there is never just one reading of a practice, and we do not find practices in a vacuum, but rather in 'systems of interdefined practices' (Brandom 1994: 163). What this 
shows is that it is possible to take a practice to be farcical. By a 'farcical practice' I mean a practice that is treated (to some extent) as if it institutes genuine commitments and entitlements, and this is reflected in participants' overt behavior, although according to some scorekeeper (who takes it to be farcical), the participants are not really committed to what the practice takes them to be committed to. This notion of farcical practices is consistent with and even necessary in Brandom's account. Notice that this is already implicit in the way Brandom formulates the example. He points to a discrepancy between the 'official rationale' of the queen's shilling as a substitute for contracts among illiterates, and its 'actual function [...] to enable "recruiting" by disguised officers': in the way Brandom presents the example, he is already placing it in a certain light, and implicitly already questioning it (note the scare quotes around 'recruiting'). It is possible to articulate this notion of farcical practices from just the basic framework of Brandom's theory. The ever-present possibility of practices counting as farcical is one way of expressing the tension, brought into play in social engagement, between merely acknowledged and actually undertaken commitments.

\section{Conclusion}

The expressive theoretical artifice of Making It Explicit is tailored to provide an explanation of the normativity of meaning in terms of social practice; how it is that certain expressions are appropriately applicable in a particular case and others not (but not which ones). This theoretical framework of a semantics that answers to pragmatics, of meaning in terms of use, constitutes a powerful theory of discursive practice, which offers a clear alternative to a representational account of meaning. I've argued that social practice, on this social-pragmatic approach, should be seen not just as cooperative, but also as contestatory. The distinction between normative statuses and practical attitudes articulates a socio-perspectival distinction between actually undertaken commitments and merely acknowledged ones, which is brought 
into play through the activity of social participants mutually holding one another to account and contesting each other's words and deeds. This tension is inherent in social engagement, which, as mutual engagement, constitutively involves discrepancies between accounts kept from different perspectives. Of course, this discussion does not do justice to all the intricacies and problems of Brandom's approach, but my aim has been to display the viability and promise of a systematic agonistic social pragmatism that can be appropriated for social and political philosophy, rather than to defend it against representationalist objections. Recent work has already provided social-pragmatic analyses of agency, power, domination, autonomy, and personhood (Anderson 2008; Erman 2010; Lance and White 2007; Rouse 2005). Elsewhere, I draw on Brandom to illuminate the notions of political legitimacy and obligation (Fossen 2011; Fossen forthcoming). In any case, such an appropriation need not be impeded by worries about undue conventionalism, since a notion of farcical practices, and thereby the possibility of a critical stance, is available within the basic framework of this theoretical approach. ${ }^{23}$

\section{Thomas Fossen}

Department of Philosophy

Utrecht University

The Netherlands

Thomas.Fossen@phil.uu.nl

\section{REFERENCES}

Acampora, C. D. (2002), 'Contesting Nietzsche', The Journal of Nietzsche Studies, 24: 1-4. Anderson, J. (2008), 'Disputing Autonomy: Second-Order Desires and the Dynamics of Ascribing Autonomy', Sats - Nordic Journal of Philosophy, 9: 7-26. 
Brandom, R. (1979), 'Freedom and Constraint by Norms', American Philosophical Quarterly, 16: 187-96.

(1994), Making It Explicit: Reasoning, Representing, and Discursive Commitment.

Cambridge, MA: Harvard University Press.

(1995), 'Knowledge and the Social Articulation of the Space of Reasons', Philosophy and Phenomenological Research, 55: 895-908.

(1997), 'Replies', Philosophy and Phenomenological Research, 57: 189-204.

(2000), 'Facts, Norms, and Normative Facts: A Reply to Habermas', European

Journal of Philosophy, 8: 356.

(2001), Articulating Reasons: An Introduction to Inferentialism. Cambridge, MA:

Harvard University Press.

(2005), 'Responses to Pippin, Macbeth and Haugeland', European Journal of

Philosophy, 13: 429-41.

(2007), 'Inferentialism and some of its challenges', Philosophy and

Phenomenological Research, 74: 651-76.

(2009), Reason in Philosophy: Animating Ideas. Cambridge, MA: Harvard University Press.

Bransen, J. (2002), 'Normativity as the Key to Objectivity: An Exploration of Robert Brandom's Articulating Reasons', Inquiry: An Interdisciplinary Journal of Philosophy, 45: 373-91.

Celikates, R. (2006), 'From critical social theory to a social theory of critique: on the critique of ideology after the pragmatic turn', Constellations, 13: 21-40.

Curtis, K. (1999), Our Sense of the Real: Aesthetic Experience and Arendtian Politics. Ithaca: Cornell University Press.

Erman, E. (2010), 'Freedom as non-domination or how to throw the agent out of the space of reasons', Journal of Power, 3: 33-51. 
Fossen, T. (2011), Political Legitimacy and the Pragmatic Turn. Utrecht: Utrecht University $\mathrm{PhD}$ dissertation.

_ (forthcoming), 'Taking Stances: Conceptualizing Political Legitimacy after the Pragmatic Turn'.

Gadamer, H.-G. (2004), Truth and Method, 2nd edition. London: Continuum.

Gibbard, A. (1996), 'Thought, Norms, and Discursive Practice: Commentary on Robert Brandom, Making It Explicit', Philosophy and Phenomenological Research, 56: 699_ 717.

Grönert, P. (2005), 'Brandom's Solution to the Objectivity Problem', Pragmatics \& Cognition, 13: 161-75.

Habermas, J. (2000), 'From Kant to Hegel: On Robert Brandom's Pragmatic Philosophy of Language', European Journal of Philosophy, 8: 322-55.

Hattiangadi, A. (2003), 'Making It Implicit: Brandom on Rule Following', Philosophy and Phenomenological Research, 66: 419-31.

Kalyvas, A. (2009), 'The Democratic Narcissus: The Agonism of the Ancients Compared to That of the (Post) Moderns', in A. Schaap (ed.), Law and Agonistic Politics, Farnham: Ashgate.

Kukla, R. and Lance, M. (2009), 'Yo!' and 'Lo!': The Pragmatic Topography of the Space of Reasons. Cambridge, MA: Harvard University Press.

Lafont, C. (2002), ‘Is Objectivity Perspectival? Reflexions on Brandom's and Habermas’s Pragmatist Conceptions of Objectivity', in M. Aboulafia, M. Bookman and C. Kemp (eds.), Habermas and Pragmatism. London: Routledge.

Lance, M. and White, H. (2007), 'Stereoscopic Vision: Persons, Freedom, and Two Spaces of Material Inference', Philosopher's Imprint, 7: 1-21.

Laurier, D. (2005), 'Pragmatics, Pittsburgh style', Pragmatics \& Cognition, 13: 141-60.

Loeffler, R. (2005), 'Normative Phenomenalism: On Robert Brandom’s Practice-Based 
Explanation of Meaning', European Journal of Philosophy, 13: 32-69.

— (2009), 'Neo-Pragmatist (Practice-Based) Theories of Meaning', Philosophy

Compass, 4: 197-218.

Nietzsche, F. (1996), 'Homer's Contest', Nietzscheana, 6: 1-8.

Owen, D. (1995), Nietzsche, Politics and Modernity. London: Sage.

Pinkard, T. (2007), 'Was Pragmatism the Successor to Idealism?', in C. Misak (ed.), New Pragmatists. Oxford: Oxford University Press.

Pippin, R. (2005), 'Brandom's Hegel', European Journal of Philosophy, 13: 381-408.

Prien, B. (2010), 'Robert Brandom on Communication, Reference, and Objectivity’, International Journal of Philosophical Studies, 18: 433.

Pritzlaff, T. (2008), 'Freedom is a Matter of Responsibility and Authority: An Interview with Robert B. Brandom', European Journal of Political Theory, 7: 365-81.

Rödl, S. (2010), ‘Normativity of Mind versus Philosophy as Explanation: Brandom's Theory of the Mind', in B. Weiss and J. Wanderer (eds.), Reading Brandom: On Making It Explicit. London: Routledge.

Rorty, R. (1979), Philosophy and the Mirror of Nature. Princeton: Princeton University Press. _ (1997), 'What Do You Do When They Call You a 'Relativist'?', Philosophy and Phenomenological Research, 57: 173-7.

Rosen, G. (1997), 'Who Makes the Rules Around Here?', Philosophy and Phenomenological Research, 57: 163-71.

Rouse, J. (2003), How Scientific Practices Matter: Reclaiming Philosophical Naturalism. Chicago: University Of Chicago Press.

(2005), 'Power/Knowledge', in G. Gutting (ed.), The Cambridge Companion to Foucault. Cambridge: Cambridge University Press.

Sabia, D. (2010), 'Defending Immanent Critique', Political Theory, 38: 684-711.

Sellars, W. (1953), 'Inference and Meaning', Mind, 62: 313-38. 
Shapiro, L. (2004), 'Brandom on the Normativity of Meaning', Philosophy and Phenomenological Research, 68: 141-60.

Siemens, H. (2002), ‘Agonal Communities of Taste: Law and Community in Nietzsche’s Philosophy of Transvaluation', Journal of Nietzsche Studies, 24: 83-112.

Springs, J. (2009), “"Dismantling the Master’s House”: Freedom as Ethical Practice in Brandom and Foucault', Journal of Religious Ethics, 37: 419-48.

Swindal, J. (2007), 'Can a discursive pragmatism guarantee objectivity? Habermas and Brandom on the correctness of norms', Philosophy \& Social Criticism, 33: 113-26.

Testa, I. (2003), 'Hegelian Pragmatism and Social Emancipation: An Interview with Robert Brandom', Constellations, 10: 554-70.

Weiss, B. and Wanderer, J. (eds.), (2010) Reading Brandom: On Making It Explicit. London: Routledge.

Wittgenstein, L. (2001), Philosophical Investigations. Oxford: Blackwell.

Zerilli, L. M. G. (2005), Feminism and the Abyss of Freedom. Chicago: University Of Chicago Press.

\footnotetext{
${ }^{1}$ For an overview, see Loeffler 2009.

${ }^{2}$ See especially the discussions in Weiss and Wanderer 2010. For social-pragmatic approaches to the notions of autonomy and personhood inspired by Brandom's work, see Anderson 2008; Lance and White 2007. For work in political philosophy that draws on Brandom, see Erman 2010; Fossen 2011; Fossen forthcoming; Springs 2009. For Brandom's own thoughts on the relevance of his approach to political philosophy, see his interviews with Pritzlaff (2008) and Testa (2003).

${ }^{3}$ See note 14 below.

${ }^{4}$ This implies that aside from the deep and acknowledged influence of the mighty dead Kant and Hegel (as well as a host of others), there is implicitly a Nietzschean moment in Brandom's thought.
} 
Hegel's notion of a struggle for recognition is also deeply conflictual, but seems to involve the prospect of a moment of harmony or reconciliation that Nietzsche (explicitly) and Brandom (implicitly) deny. See note 18 below.

${ }^{5}$ This is of course not the only way pragmatic and interpretive approaches can be defended against charges of uncritical positivism or conventionalism; see, for instance, Sabia 2010; Celikates 2006. My concern is to show how this possibility is immanently connected to Brandom's theoretical framework. ${ }^{6}$ A classical critique of representationalism was offered by Brandom's teacher Richard Rorty (1979).

7 'A distinction becomes a dualism when its components are distinguished in terms that makes their characteristic relations to one another ultimately unintelligible.' (Brandom 1994: 615)

${ }^{8}$ On this point there is a strong parallel with the work of Jürgen Habermas. See the exchange between them in Brandom 2000; Habermas 2000.

${ }^{9}$ I say 'in first instance', because Brandom thinks it is possible to reason by oneself (monologically) once one has developed the capacity to reason with others (dialogically); see Brandom 1994: 497. He also thinks we can attribute a derivative sense of intentionality to non-linguistic animals.

${ }^{10}$ Not everything that can be said counts as an assertion, but Brandom holds that assertion has a priority among forms of linguistic expression; Brandom 1994: 172. Kukla and Lance (2009) challenge this priority of assertion.

${ }^{11}$ Brandom argues that treating all norms as explicit rules or principles makes the normativity of their application unintelligible, leading to an infinite regress. As Wittgenstein famously stated, there is 'a way of grasping a rule which is not an interpretation, but which is exhibited in what we call "obeying the rule" and "going against it" in actual cases' (Wittgenstein 2001 §201; cited in Brandom 1994: 21). ${ }^{12}$ Semantic inferentialism as an account of conceptual content is challenged (without rejecting Brandom's social pragmatism as a whole) in Loeffler 2005; Shapiro 2004.

${ }^{13}$ But see Rouse (2003: 184-262) and Kukla and Lance (2009), who argue it should be even more embodied.

${ }^{14}$ See Gibbard 1996; Habermas 2000; Hattiangadi 2003; Laurier 2005: 150-158; Loeffler 2005; Rosen 1997; Rödl, 2010: 70-76.

${ }^{15}$ For instance: 'The normative significances of performances and the deontic states of performers are 
instituted by the practice that consists in keeping score by adopting attitudes of attributing and acknowledging them' (Brandom 1994: 166, cf. 48, 626). This goes not just for the conceptual normativity that is central in Making It Explicit. As he states elsewhere, 'all normative statuses are ultimately social statuses, instituted by us' (Pritzlaff 2008: 371, 367).

${ }^{16}$ Brandom claims that this possibility is intelligible due to the representational dimension implicit in discursive practice, which offers 'a way of understanding how our scorekeeping practices can confer conceptual contents about whose proper applicability and consequences we can not only each but all be in error' (Brandom 1994: 497). Brandom's affirmation of objectivity has generated a lot of discussion. See Grönert 2005; Habermas 2000: 332-337; Lafont 2002; Prien 2010; Swindal 2007. ${ }^{17}$ My understanding of the agon draws on Nietzsche and several recent interpretations of his thought; especially Nietzsche 1996; Owen 1995; Siemens 2002; Acampora 2002. Here, I am using it as a device that helps to illuminate Brandom's thought, so I won't go into the interpretation of Nietzsche. On the ancient Greek origins of the agon, especially as pertains to politics, see Kalyvas 2009. ${ }^{18}$ There is an interesting parallel on this point with an eminently political thinker: Hannah Arendt. On Linda Zerilli's interpretation: 'We have the world in common because we view it from different perspectives. Absent those perspectives we lose 'the sameness of the object', its realness or 'objective' quality. Rather than threaten our shared sense of worldly reality, in other words, plurality generates it. Plurality — if we take proper account of it—saves us from both objectivism and subjectivism, and therefore from risking dogmatism or skepticism, Arendt suggests' (Zerilli 2005: 125-164, here 140; cf. Curtis 1999: 23-66). For Zerilli's Arendt, this essentially perspectival sense of objectivity is what marks off the political from the conceptual, empirical and scientific world. In this vein, we might suggest that according to Brandom's thought even the conceptual, empirical, and scientific, is political.

${ }^{19}$ The 'paradigm of communication as joint possession of some common thing is relinquished in favor of [...] a paradigm of communication as a kind of cooperation in practice' (Brandom 1994: 485; cf. Brandom 2007: 667). Commentators also tend to stress the cooperative aspect. Jan Bransen, for example, states: 'The game [of giving and asking for reasons] is not competitive: entitlements gained by a player are not lost by another' (Bransen 2002: 387; cf. Prien 2010: 456). While this point about 
the inheritance of entitlements is correct, it does not negate the element of contestation in determining what counts as an entitlement.

${ }^{20}$ As David Owen argues, 'our practices are agonistic in a twofold sense: firstly, practices are characterised by historical communities in which persons contest with themselves and each other to achieve excellence; and, secondly, practices are characterised by the contestation of plural perspectives concerning the character of excellence' (Owen 1995: 144).

${ }^{21}$ Brandom makes this point in response to a question from Richard Rorty: 'Rorty asks whether any principle can claim a higher status than that of being presupposed by some de facto existing practice. Yes and no. What is presupposed by any existing practice can be rationally criticized—criticized, that is to say, on the basis of reasons that can be understood as holding those presuppositions up to assessment in the light of how it actually is with what the presuppositions are presuppositions about. But such criticisms will ultimately express (and in that sense 'rest on') other de facto existing practices. There is no Archimedean point, independent of all practices, from which to criticize any of them. The world only comes into view through the deployment of some concepts or others.' (Brandom 1997: 201; cf. Rorty 1997)

${ }^{22}$ Brandom doesn't really address this point in his reply to Pippin (Brandom 2005).

${ }^{23}$ I would like to thank Joel Anderson, Bert van den Brink, and Patchen Markell for their constructive comments on various earlier versions of this paper. 